\title{
Aquilo que se vê: do olhar sobre o retrato de memórias de quem já me foi próximo
}

\author{
Matheus Guilherme de Oliveira ${ }^{1}$
}

Só se vê o que se olha, diria Merleau-Ponty, em seu conhecido livro O olho e o Espirito. Isto é, por mais que a visão toque os retratados nessa série, o olhar já não os toca, diante da pandemia que passamos nesse ano tão turbulento. O olhar agora, vivencia-se através de uma tela digital, a sociedade do cansaço, aquela que tem seus olhos cobertos por uma vasta gama de imagens, fazendo com que muitos sentimentos sejam esquecidos, chega cada vez mais próxima de se tornar real. A pandemia possibilitou os olhos enxergarem novas possibilidades de conexões com o outro, agora, os olhos já não se cruzam mais cara a cara, mas mídia a mídia. Como então, poderia a pintura resistir a essa avalanche? Como estar diante do outro se ficamos prisioneiros de algo que nem ao menos podemos ver? Pois a pintura pode responder a essa indagação. Aquilo que se vê propõe tocar no cerne no que diz respeito à memória e à experiência de estar ali, com quem agora está mais distante. Os retratos pintados foram iniciados antes da quarentena com modelos vivos, posando silenciosamente frente ao pintor, foi continuado durante ela, através das selfies que encarecidamente pedia para o modelo retirar e me enviar, procuro através da foto recebida

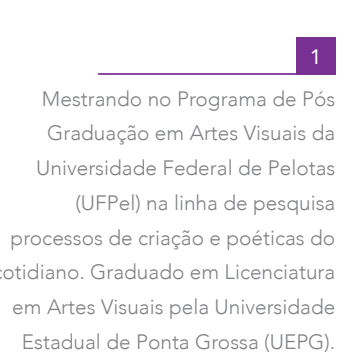


Aquilo que se vê: do olhar sobre o retrato de memórias de quem já me foi próximo Matheus Guilherme de Oliveira

em meu celular, estar diante da lembrança que temos juntos. É claro, o modelo, frente a frente seria muito melhor. Poderia ver as gotas de suor, escorrendo sobre a testa. Poderia ver o brilho em seus olhos, o rio que corre sobre eles. Poderia sentir, ver e encarar aquela pele retratada de forma lenta sobre uma tela de algodão, de tamanho pequeno, tornando ainda mais intimista o que é pictórico. As camadas grossas de tinta a óleo ressaltam (im) perfeições humanas, olheiras, as marcas do tempo. Agambem escrevera em Rostos que este é paixão da revelação, paixão da linguagem, esse, traduz a palavra, revela impossibilidade de ser segredo, emerge como castidade ou perturbação, descaramento ou vergonha. Os retratos salientam essas vergonhas ou perturbações, mas trazem consigo também, cargas de emoção, onde através dos olhos, busca-se ver ou estar diante daquele que está retrato. Seja esse, um amigo, um irmão, um tio, uma vó. Todos rios, eu montanha, aprendo um pouco mais, a partir de cada pincelada que constrói o rosto, daquele que, agora me vê. De certo modo, estou mais próximo agora que todos me olham, com um olhar fixo, repletos de afeto, fixados sobre a parede borrada de tinta do meu querido quartELIÊR

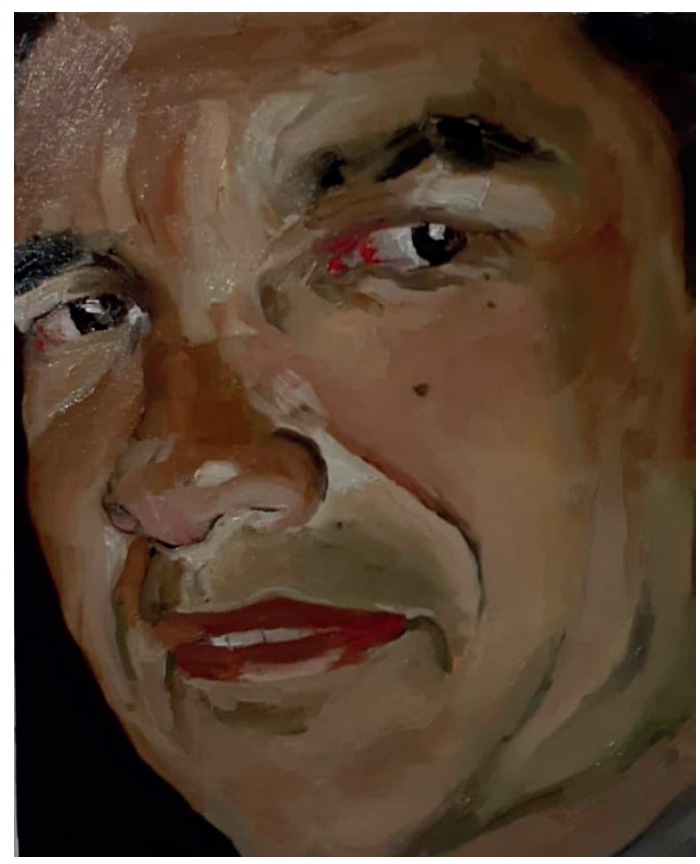

Pai do artista com 47 anos. 
Aquilo que se vê: do olhar sobre o retrato de memórias de quem já me foi próximo Matheus Guilherme de Oliveira

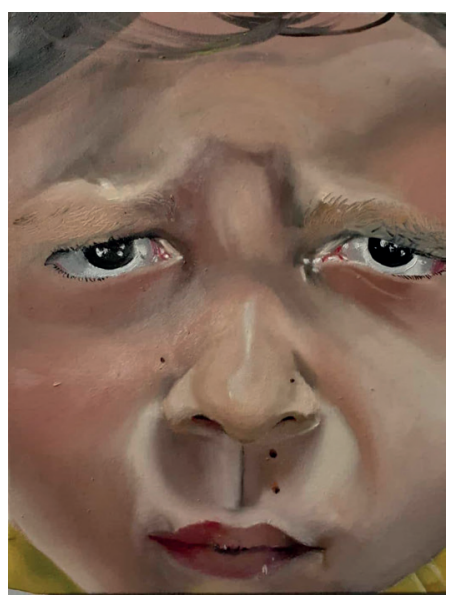

Murilo com 4 anos

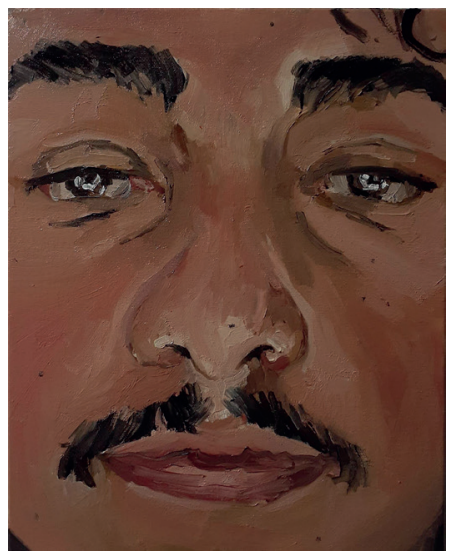

Carlos com 21 anos

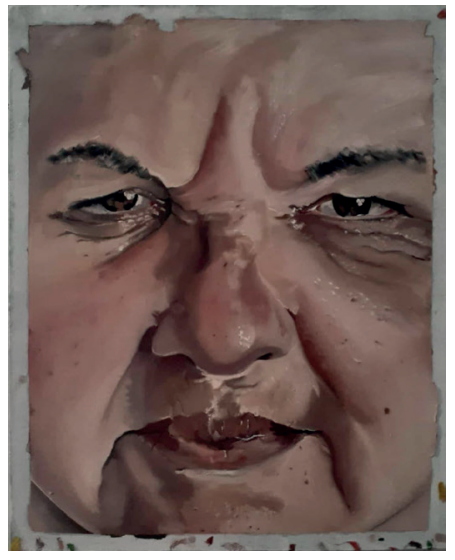

Avó do artista com 62 anos 
Aquilo que se vê: do olhar sobre o retrato de memórias de quem já me foi próximo Matheus Guilherme de Oliveira

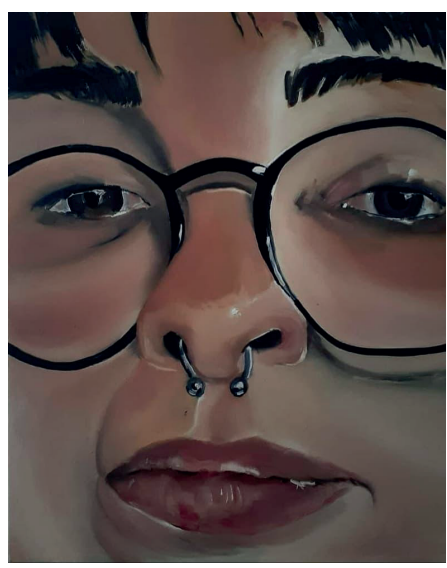

Jaqueline com 25 anos

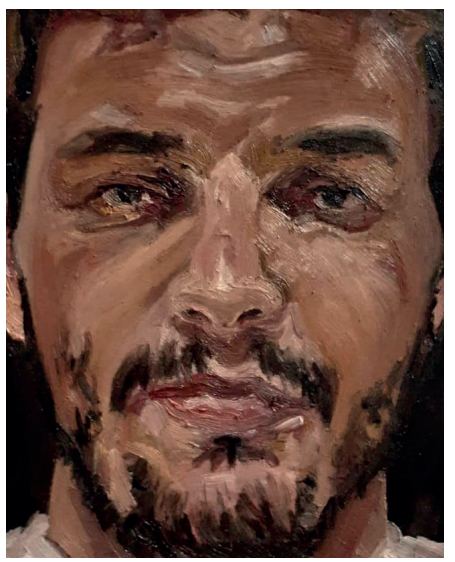

Juca com 28 anos

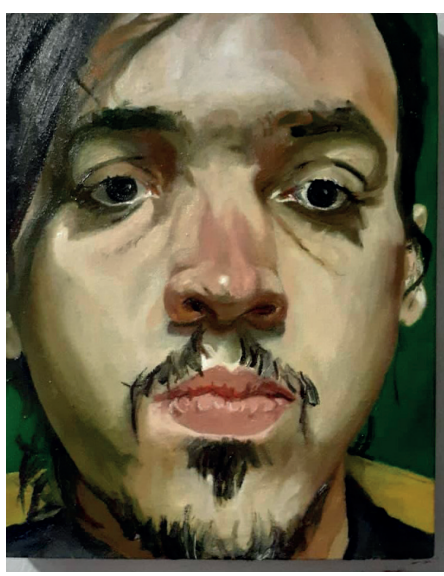

Luis com 24 anos 
Aquilo que se vê: do olhar sobre o retrato de memórias de quem já me foi próximo Matheus Guilherme de Oliveira

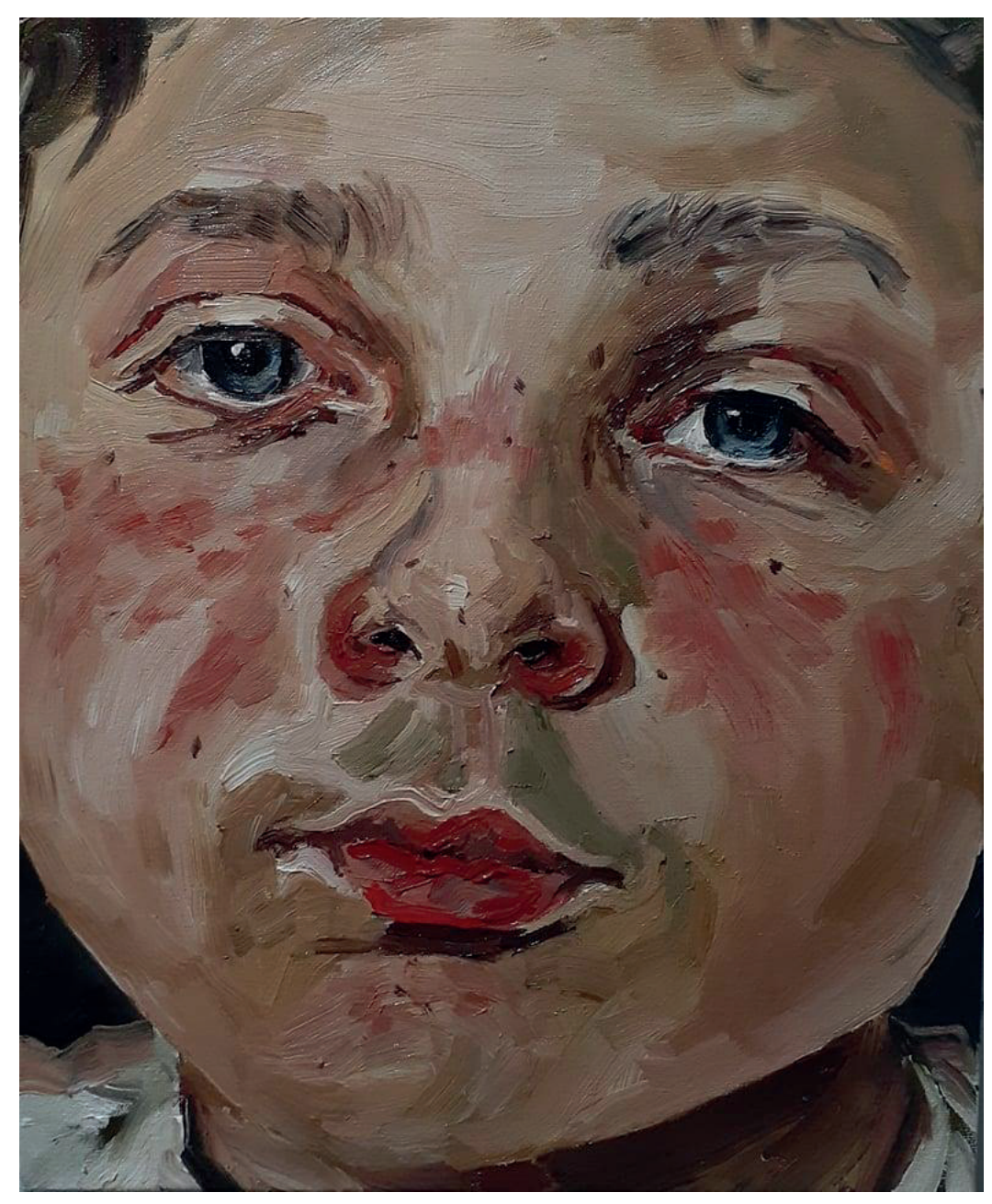

Nicolas com 12 anos

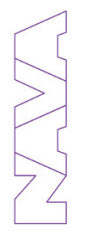

